\title{
A Model-Based Optimisation Approach for Process Synthesis of Olefins from Petroleum with Application to the Malaysian Petrochemical Industry
}

\author{
Cheng Seong Khor ${ }^{1,2^{*}}$ \\ ${ }^{I}$ Chemical Engineering Department, Universiti Teknologi PETRONAS, Bandar Seri Iskandar, \\ 31750 Tronoh, Perak, Malaysia. \\ ${ }^{2}$ Centre for Process Systems Engineering, Institute of Autonomous Systems, \\ Universiti Teknologi PETRONAS, Bandar Seri Iskandar, 31750 Tronoh, Perak, Malaysia
}

\begin{abstract}
The shale gas revolution has rekindled interest in olefins production due to the abundance of etha ne as a raw material resource. However, the main technology still revolves around the cost-intensive distillation operation. Hence this work aims to investigate the economic optimisation of olefins synthesis from petroleum in the light of recent developments. A model-based approach is applied to determine the optimal sequencing of separation and reaction processes for a multi-component hydrocarbon mixture feed to produce mainly ethylene and propylene. a mixed-integer linear program (MILP) is formulated based on a superstructure that captures numerous plausible synthesis alternatives. The model comprises linear mass balance reactor representation and simple sharp distillation based on split fractions for product recovery. Integer binary variablesis used for selecting the task for equipment and continuous variables for representing the flowrate of each task. To expedite converging to an optimal solution of a least total annualised cost configuration, the formulation is appended with logical constraints on the design and structural specifications derived from heuristics based on practical knowledge and experience. The modelling approach on actual case studies based on two such petrochemical facilities operating in Malaysia is implemented. Additionally, the solution analysis is enriched with the investigation on a second- and third-best (suboptimal) configurations obtained through appropriate integer cuts as constraints to the model. The results show good agreement with existing plant configurations, thus substantiating the value and verification of the proposed model-based optimisation approach.
\end{abstract}

Keywords: ethylene production; shale gas; cold ends processing; state-task network (STN); integer cuts; total annualised cost

\section{Notations}

\section{Sets and Indices}

$I_{j} \quad$ components $i$ in the feed stream to task $j$

$J \quad \operatorname{tasks} j$

IJ all pairs of tasks $i$ and their associated products $j$

$I_{j}^{\mathrm{D}} \quad$ components in the distillate (D) of task $j$ 


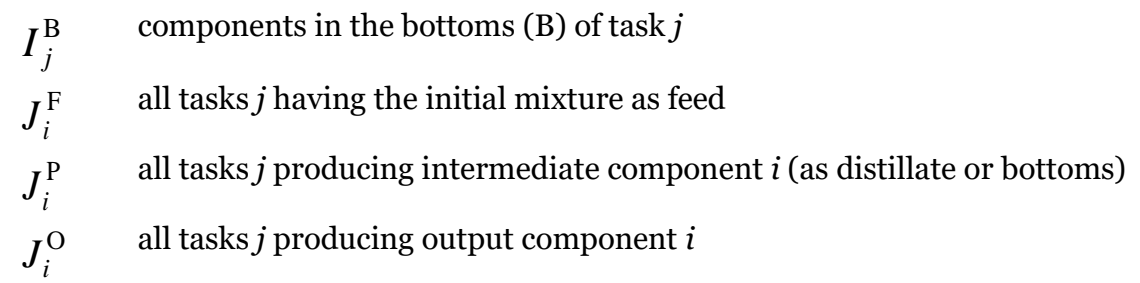

\section{Parameters}

$L \quad$ plant life (year)

$\mathrm{CC}_{j} \quad$ capital cost for purchasing and installing equipment for task $j$

$\mathrm{OC}_{j} \quad$ operating cost for task $j$

$H \quad$ hours of plant operation per annum

\section{Variables}

$x_{i} \quad$ mol fraction of component $i$ in the feed composition

$F^{\mathrm{F}} \quad$ flowrate of the initial mixture to be processed

$F_{j} \quad$ feed flowrate to each task $j$

$y_{j}^{i} \quad$ binary variable on the existence of a stream with component $j$

\section{INTRODUCTION}

The shale gas revolution in the United States of America has renewed interest in the production of ethylene and olefins as spurred by a significant shift in raw materials. Abundant shale gas production has availed low-cost ethane that is driving a resurgence in the petrochemical industry in the US with wide-ranging repercussions to material, energy, and trade flows worldwide. It is projected that by 2023, approximately $50 \%$ of global ethylene production will be from the gaseous feedstock of ethane or liquefied petroleum gas (LPG) from natural gas with the remaining produced from the liquid feedstock of naphtha from petroleum refinery gas streams (World LPG Association (WLPGA) 2019). When crude oil prices fell in 2014, there was increased emphasis on balancing between these gaseous (light) and liquid (heavy) feedstock.

Ethylene and other similar light olefins with low molecular weights such as propylene are basic petrochemical building blocks. The conventional olefins production process requires steam or thermal cracking of a mainly light alkanes or paraffins feed - the key technology centres around distillation, which remains an energy-intensive and high-cost operation. Moreover, separating multicomponent mixtures into pure or multi-component product streams using distillation gives rise to many possible sequences of distillation columns with options for reactions to increase the desired yields of certain hydrocarbon particularly ethylene (Ren et al., 2006).
Hence, there is an economic incentive in optimally selecting the best separation sequence for a particular process using a suitable procedure. The optimal separation synthesis sequence remains a challenging problem in chemical process design, particularly distillation column sequencing due to exponentially increasing number of structural alternatives (Puigjaner et al., 2008; Caballero et al., 2009).

A dominant method in the literature for the past decade is superstructure optimisation using mathematical programming (Khor et al., 2012a), which is the focus of this work. The approach involves developing a superstructure that contains many, if not all possible sequences in a process synthesis problem and formulating an optimisation model based on the superstructure that often gives rise to a mixedinteger linear (MILP) or nonlinear program (MINLP) (Westerberg et al., 1996; Grossmann et al., 2005).

An early work on superstructure optimisation for distillation sequencing by Andrecovich and Westerberg (1985) postulates a superstructure that accounts for the separation tasks in each column and their interconnections assuming sharp separation. The formulation employs discrete variables on equipment selection and continuous variables on flowrates and split fractions, which leads to a mixed-integer model.

Floudas (1987) investigates superstructure optimisation for a general separation problem by considering the interconnections of a fixed number of sharp separators represented by simple mass balances, which eliminates a need for binary variables. Aggarwal and Floudas (1990) relax 
the sharp split assumption by optimising the distribution of the light and heavy key components in a superstructure with recoveries as optimisation variables. They develop a rigorous cost minimisation objective function through simulation and regression analysis.

Subsequent work has also applied and extended the integration of process simulators in separation sequencing and general flowsheet optimisation (Dokurno et al., 1983; Caballero et al., 2005; Caballero et al., 2007). The implementation of such a technique can be supported with a surrogate modelling approach in handling detailed nonlinear process relations (Caballero et al., 2008). More recent work involves superstructure-based MINLP approach to address thermally-coupled heat-integrated distillation sequences (Caballero et al., 2013).

This work presents a model-based approach for optimising both the reaction and separation functions in the synthesis of olefins mainly ethylene from petroleum-based sources. To expedite the convergence to optimality, the model incorporates heuristic-based logical constraints as derived from insights obtained from past design experience and engineering knowledge of the processes concerned. The rest of the paper is organised as follows. Section 2 states the problem addressed in this work. Section 3 presents the proposed superstructure and MILP model formulation to handle the problem including the additional logical constraints. Section 4 reports the model implementation on case studies of actual operating petrochemical plants in Malaysia and discusses the results before concluding.

\section{PROBLEM STATEMENT}

The optimal processing sequence of an olefins mixture given the composition and total feed flowrate (based on product yields from a thermal cracking unit), availability and the maximum capacity of process units, operating cost of utilities, and product demands will be addressed. The aim is to determine the selection of the separation and reaction tasks (binary variables) and the associated stream flow rates (continuous variables) that satisfy the minimum total annualised cost for ethylene production.

\section{OPTIMISATION MODEL FORMULATION}

A superstructure optimisation approach to formulate an MILP on the separation and reaction sequences for processing an olefins mixture mainly to produce ethylene was employed. Linear mass balance reactor models are adopted to represent material conversion. The distillation columns are assumed to perform simple splits involving one feed and two products consisting of distillate and bottoms as well as sharp separation in which an entering component leaves to give complete (100\%) recovery.

Figure 1 shows a superstructure representation of the cryogenic- and distillation-based separation section, also called the cold ends, for processing the cracked gas (from steam cracking) after compression, acid gas removal, and scrubbing. A superstructure type that is an intermediate between the conventional representations of state-task network (STN) (Sargent 1998) and state-equipment network (SEN) (Smith et al., 1995) is adopted, yet has the advantages of both in terms of fewer constraints and good computational performance to attain convergence towards optimality (Caballero et al., 1999). the superstructure was developed to include many alternative separation and reaction sequences for the cold-ends by combining single operation or task through mixers and splitters modelled as single-choice units (i.e., by selecting only one input stream from a mixer and only one output stream from a splitter).

\section{A. Superstructure Representation}

The superstructure in Figure 1 represents processing of the cracked gas, which contains many hydrocarbon compounds (also called pyrolysis oil and pyrolysis gasoline or pygas) through a sequence of reaction and separation steps to produce the main products of ethylene $\left(\mathrm{C}_{2} \mathrm{H}_{4}\right)$ and propylene $\left(\mathrm{C}_{3} \mathrm{H}_{6}\right)$ besides various by-products. The $\mathrm{C} 1$ distillation task can be assigned as Demethaniser $\left(\mathrm{DeC}_{1}\right)$, High-Pressure Depropaniser $\left(\mathrm{HPDeC}_{3}\right)$, or Debutaniser $\left(\mathrm{DeC}_{4}\right)$. The overhead stream from $\mathrm{C} 1$ has a number of possible outlets: $\mathrm{C} 2$ task comprising $\mathrm{DeC}_{1}$, Deethaniser $\left(\mathrm{DeC}_{2}\right)$, or $\mathrm{HPDeC}_{3}$; Pressure Swing Absorber (PSA task); Acetylene Hydrogenation Reactor (AHR of R1 task); or Extractive Distillation (ED of $\mathrm{C}_{4}$ task). The bottoms stream from $\mathrm{C} 1$ task 
can be directed to three possible further processing options, namely $\mathrm{C}_{3}$ task comprising $\mathrm{DeC}_{2}$ with two possible component splits or Debutaniser $\left(\mathrm{DeC}_{4}\right), \mathrm{C}_{5}$ task of LowPressure Depropaniser $\left(\mathrm{LPDeC}_{3}\right)$ with two possible component splits, or Gasoline Hydrogenation Reactor (GHR of R4 task).

The conditional destinations of $\mathrm{C} 2$ task overhead stream are PSA (of PSA task), AHR (of R1 task), or ED (of C4) tasks while the bottoms stream of $\mathrm{C} 2$ task has three possible outlets: $\mathrm{DeC}_{2} / \mathrm{DeC}_{4}$ (of $\mathrm{C}_{3}$ task), $\mathrm{LPDeC}_{3}$ (of $\mathrm{C}_{5}$ task), or $\mathrm{ED}$ (of $\mathrm{C}_{10}$ task). The $\mathrm{C}_{3}$ task overhead stream goes to either AHR (of R1 task) or ED (of $\mathrm{C}_{4}$ task) whereas that of the bottoms stream ends up in $\mathrm{LPDeC}_{3}$ (of $\mathrm{C}_{5}$ task) or Butadiene Hydrogenation Reactor (BHR of $\mathrm{R}_{3}$ task).

Possible dispositions for the outlet stream of AHR (of R1 task) are PSA (of PSA task), Ethylene Splitter (ES of C11 task), back-end $\mathrm{DeC}_{1}$ (of $\mathrm{C} 6$ task), or back-end $\mathrm{DeC}_{2}$ (of $\mathrm{C} 6$ or $\mathrm{C} 9$ task). Besides obtaining acetylene as the bottoms stream, ED (of $\mathrm{C}_{4}$ task) column overhead stream has four possible destinations, namely ES (of C11 task), back-end $\mathrm{DeC}_{1}$ (of C6 or C8 task), back-end $\mathrm{DeC}_{2}$ (of C6 or C9 task), or Propadiene Hydrogenation Reactor (PHR of R2 task).

The overhead stream from $\mathrm{LPDeC}_{3}$ (of $\mathrm{C}_{5}$ task) ends up in PHR (of R2 task) while the bottoms stream can undergo further processing in $\mathrm{BHR}$ (of $\mathrm{R}_{3}$ task), back-end $\mathrm{DeC}_{4}$ (of $\mathrm{C}_{7}$ task), or olefins cracking unit (OCU of OCU task). C6 task overhead stream goes to either PSA (of PSA task) or $\mathrm{DeC}_{1}$ (of C8 task) while the bottoms stream to $\mathrm{DeC}_{2}$ (of $\mathrm{C} 9$ task) or PHR (of R2 task). $\mathrm{DeC}_{4}$ (of $\mathrm{C}_{7}$ task) produces an overhead stream as feed to BHR (of R3 task) and that of a bottoms stream to GHR (of R4 task). $\mathrm{DeC}_{1}$ (of C8 task) overhead stream is further processed in PSA while that of its bottoms stream in $\mathrm{ES}$ (of C11 task). For $\mathrm{DeC}_{2}$ (of C9 task), its overhead stream goes to ES (of C11 task) while its bottoms stream to PHR (of R2 task).

Table 1. Summary of states and tasks for superstructure representation in

\begin{tabular}{|c|c|c|c|c|}
\hline \multirow[t]{2}{*}{ Task } & \multirow[t]{2}{*}{ Unit } & \multirow[t]{2}{*}{$\begin{array}{l}\text { Origin State } \\
(\mathrm{oh} / \mathrm{bt})^{*}\end{array}$} & \multicolumn{2}{|c|}{$\begin{array}{l}\text { Destination } \\
\text { State }\end{array}$} \\
\hline & & & Column Overhead & Column Bottoms \\
\hline $\mathrm{C} 1$ & $\mathrm{DeC}_{1} / \mathrm{HPDeC}_{3} / \mathrm{DeC}_{4}$ & Feed & $\mathrm{C} 2 / \mathrm{PSA} / \mathrm{R} 1 / \mathrm{C} 4$ & $\mathrm{C}_{3} / \mathrm{C}_{5} / \mathrm{C}_{4}$ \\
\hline $\mathrm{C} 2$ & $\mathrm{DeC}_{1} / \mathrm{DeC}_{2} / \mathrm{HPDeC}_{3}$ & $\mathrm{C} 1 \mathrm{oh}$ & $\mathrm{PSA} / \mathrm{R} 1 / \mathrm{C} 4$ & $\mathrm{C}_{3} / \mathrm{C}_{5} / \mathrm{C}_{10}$ \\
\hline $\mathrm{C}_{3}$ & $\mathrm{DeC}_{2} / \mathrm{DeC}_{4}$ & $\mathrm{C} 1 \mathrm{bt} / \mathrm{C}_{2} \mathrm{bt}$ & $\mathrm{R} 1 / \mathrm{C} 4$ & $\mathrm{C}_{5} / \mathrm{R}_{3}$ \\
\hline $\mathrm{C}_{4}$ & ED & $\mathrm{C} 1 \mathrm{oh} / \mathrm{C} 2 \mathrm{oh} / \mathrm{C}_{3}$ oh & C6/C8/C9/C11/R2 & - (terminal) \\
\hline $\mathrm{C}_{5}$ & $\mathrm{LPDeC}_{3}$ & $\mathrm{C} 1 \mathrm{bt} / \mathrm{C}_{2} \mathrm{bt} / \mathrm{C}_{3} \mathrm{bt}$ & $\mathrm{R} 2$ & $\mathrm{R}_{3} / \mathrm{C}_{7} / \mathrm{OCU}$ \\
\hline C6 & $\mathrm{DeC}_{1} / \mathrm{DeC}_{2}$ & C4 oh/R1 & PSA/C8 & C9/R2 \\
\hline $\mathrm{C}_{7}$ & $\mathrm{DeC}_{4}$ & $\mathrm{C}_{5} \mathrm{bt}$ & $\mathrm{R} 3$ & $\mathrm{R} 4$ \\
\hline $\mathrm{C} 8$ & $\mathrm{DeC}_{1}$ & C4 oh/R1/C6 oh & PSA & C11 \\
\hline C9 & $\mathrm{DeC}_{2}$ & $\mathrm{C} 4 \mathrm{oh} / \mathrm{R} 1 / \mathrm{C}_{4} \mathrm{bt}$ & C11 & R2 \\
\hline C10 & Extractive Distillation (ED) & $\begin{array}{c}\mathrm{C}_{3} \mathrm{bt} / \mathrm{C}_{5} \mathrm{bt} / \mathrm{C}_{7} \\
\text { oh/C2 bt }\end{array}$ & - (terminal) & - (terminal) \\
\hline C11 & Ethylene Splitter (ES) & C9 oh & - (terminal) & - (terminal) \\
\hline $\mathrm{C} 12$ & Propylene Splitter (ES) & $\mathrm{R} 2$ & - (terminal) & - (terminal) \\
\hline $\mathrm{R} 1$ & $\begin{array}{c}\text { Acetylene Hydrogenation } \\
\text { Reactor (AHR) }\end{array}$ & $\mathrm{C} 1 / \mathrm{C}_{2} / \mathrm{C}_{3}$ & $\mathrm{PSA} / \mathrm{C}$ & 9/C10 \\
\hline $\mathrm{R} 2$ & $\begin{array}{c}\text { Propadiene Hydrogenation } \\
\text { Reactor (PHR) }\end{array}$ & C5 oh/C6 bt/C9 bt & & \\
\hline $\mathrm{R} 3$ & $\begin{array}{c}\text { Butadiene Hydrogenation } \\
\text { Reactor (BHR) }\end{array}$ & $\mathrm{C}_{3} \mathrm{bt} / \mathrm{C}_{5} \mathrm{bt} / \mathrm{C}_{7} \mathrm{oh}$ & $-($ te & nal) \\
\hline
\end{tabular}




\begin{tabular}{|c|c|c|c|}
\hline R4 & $\begin{array}{c}\text { Gasoline Hydrogenation Reactor } \\
\text { (GHR) }\end{array}$ & C1 bt/C7 bt & - (terminal) \\
\hline OCU & Olefins cracking unit & C5 bt & - (terminal) \\
\hline PSA & Pressure swing absorber & $\begin{array}{c}\mathrm{C} 1 \mathrm{oh} / \mathrm{C} 2 \mathrm{oh} / \mathrm{R} 1 / \mathrm{C} 4 \\
\mathrm{oh} / \mathrm{C} 6 \mathrm{oh} / \mathrm{C} 8 \mathrm{oh}\end{array}$ & - (terminal) \\
& & & \\
\hline
\end{tabular}

*Denotes overhead (oh) or bottoms streams (bt) for distillation columns

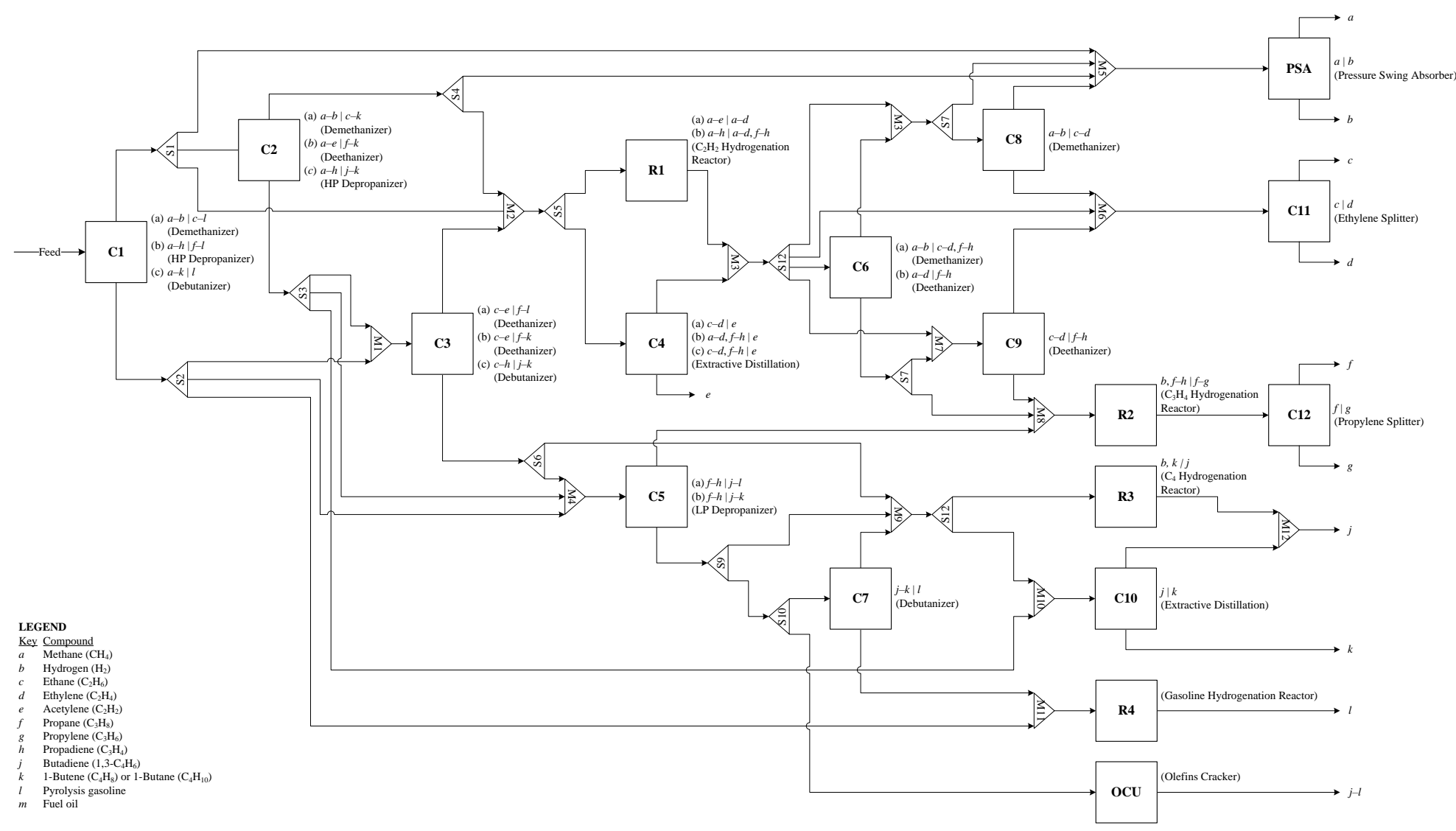

Figure 1. Superstructure representation for the production of olefins

\section{B. Material Balances}

The material balances describe the permissible routes by which material may flow into and out of a task for a distillation column or a reactor in the superstructure. For a sharp distillation column, a feed stream is separated into the overhead (or distillate) and bottoms product streams consisting of pure components, i.e., they are recovered either at the top or at the bottoms, respectively. The split fraction of the total feed for the distillate $\xi_{j}^{i, D}$ is given by:

$$
\xi_{j}^{i, D}=\frac{\sum_{i \in I_{j}^{D}} x_{i}}{\sum_{i \in I_{j}} x_{i}}, j \in J
$$

and the split fraction for that of the bottoms $\xi_{j}^{i, B}$ is:

$$
\xi_{j}^{i, B}=\frac{\sum_{i \in I_{j}^{B}} x_{i}}{\sum_{i \in I_{j}} x_{i}}, j \in J .
$$

In the case of non-sharp separation, a "half-rule" for the non-pure components was applied, which are recovered in both the overhead and bottoms, in which one-half of the mol fraction of the feed is added to the components in the distillate, and the other half is added to those recovered in the bottoms. The assumption yields the following relations for the split fractions, respectively:

$$
\xi_{j}^{i, D}=\frac{\sum_{i \in I_{j}^{D}} x_{i}+\frac{1}{4} \sum_{i^{\prime} \in I_{j}^{D} \backslash\{i\}} x_{i}}{\sum_{i \in I_{j}} x_{i}+\frac{1}{2} \sum_{i^{\prime} \in I_{j}^{D} \backslash\{i\}} x_{i}}, j \in J,
$$




$$
\xi_{j}^{i, B}=\frac{\sum_{i \in I_{j}^{B}} x_{i}+\frac{1}{4} \sum_{i^{\prime} \in I_{j}^{B} \backslash\{i\}} x_{i}}{\sum_{i \in I_{j}} x_{i}+\frac{1}{2} \sum_{i^{\prime} \in I_{j}^{B} \backslash\left\{i i^{\prime}\right.} x_{i}}, j \in J .
$$

The feed to the main distillation and reaction system for product recovery is given by:

$$
F^{F}=\sum_{j \in J_{i}^{F}} F_{j}
$$

Each intermediate component $i$ produced by a task equals the amount of that component $i$ fed to a task $j$ that further separates the product:

$$
\sum_{j \in J_{i}^{F}} F_{j}=\sum_{j \in J_{i}^{P}} \xi_{j}^{i} F_{j}, \forall i \in I^{I}
$$

where $F_{j}^{F}$ is the total feed flow rate to a task $j, J_{i}^{P}$ is the set of all tasks $j$ producing a known intermediate component $i$ as distillate or bottoms, $J_{i}^{F}$ is the set of all tasks $j$ having intermediate component $i$ as feed, and $I^{\mathrm{I}}$ is the set of all intermediate components. The balance is written for each intermediate component. Note that the intermediate products from an extractive distillation unit are also treated in the same manner by aggregating the components accordingly.

\section{Logical Constraints}

Logical constraints in the form of switching constraints are imposed to select the tasks by "switching" them on or off to ensure that the non-existence of a task corresponds to no input flow. A big- $M$ formulation for such logical constraints that relate the continuous flowrate variables and the integer o-1 variable on task selection as follows:

$$
F_{j} \leq M_{j} y_{j}, \forall j \in J
$$

where $M_{j}$ is the big- $M$ constant that can be taken as the maximum capacity of the processing unit for a task $j$ to stipulate an upper bound on its inlet flow rate.

\section{Heuristic-Based Logical Constraints}

Heuristic-based linear, logical constraints or cutting planes derived from process engineering insights are incorporated in the model formulation to expedite convergence to optimality. These logical constraints or logic cuts serve two purposes: to enforce structural specifications on interconnectivity relationships among the component streams and tasks in the superstructure as well as to stipulate design specifications as based on engineering knowledge, past design experience, and rules of thumb (Khor et al., 2011; Khor et al., 2012b). The logic cuts can be developed based on propositional logic expressions that are subsequently reformulated into algebraic constraints (Raman et al., 1991).

The heuristic-based cuts on structural specifications can be categorised into those that involve: (1) the feed or inlet streams to tasks, and (2) the overhead and bottom products of the distillation columns as well as the reactor products. The general formulation of such a logic cut is given by:

$$
y_{j}^{i} \leq \sum_{j \in J_{i}^{O}} y_{j}^{i}, \forall(i, j) \in I J
$$

On the other hand, the propositional logic on design specification for the tasks processing the feed to the first distillation column (C1) involves selecting exactly one task from among the demethaniser (task C1a), the high-pressure depropaniser (C1b), and the debutaniser (C1c):

$$
Y_{\mathrm{C} 1 \mathrm{a}}^{a-b \mid c-l} \oplus Y_{\mathrm{C} 1 \mathrm{~b}}^{a-h \mid f-l} \oplus Y_{\mathrm{C} 1 \mathrm{c}}^{a-k \mid l}
$$

The logic expression is reformulated as the following constraint:

$$
y_{\mathrm{C} 1 \mathrm{a}}^{a-b \mid c-l}+y_{\mathrm{C} 1 \mathrm{~b}}^{a-h \mid f-l}+y_{\mathrm{C} 1 \mathrm{c}}^{a-k \mid l}=1
$$

Thus, the general formulation of such a logic cut on the design specification for the tasks processing an initial mixture enforce that exactly one of the tasks associated with equipment is selected:

$$
\sum_{j \in J_{i}^{F}} y_{j}=1
$$


The logic cuts on design specifications for the tasks that produce intermediate components stipulate that at most, one of the tasks associated with equipment is selected:

$$
\sum_{j \in J_{i}^{G}} y_{j} \leq 1
$$

To illustrate an instance of such a logical constraint, we consider the propositional logic for the feed to the second distillation column $(\mathrm{C} 2)$ to select at most one task from among the demethaniser (C2a), the deethaniser (C2b), and the high-pressure depropaniser (C2c):

$$
Y_{\mathrm{C} 2 \mathrm{a}}^{a-b \mid c-k} \vee Y_{\mathrm{C} 2 \mathrm{~b}}^{a-e \mid f-k} \vee Y_{\mathrm{C} 2 \mathrm{c}}^{a-h \mid j-k}
$$

which is reformulated as:

$$
y_{\mathrm{C} 2 \mathrm{a}}^{a-b \mid c-k}+y_{\mathrm{C} 2 \mathrm{~b}}^{a-e \mid f-k}+y_{\mathrm{C} 2 \mathrm{c}}^{a-h \mid j-k} \leq 1
$$

The compact model formulation is given by:

$$
\begin{aligned}
& \min \quad \sum_{j \in J}\left(\frac{1}{L} \mathrm{CC}_{j} y_{j}+\mathrm{OC}_{j} F_{j} H\right) \\
& \text { s.t. } F^{F}=\sum_{j \in J_{i}^{F}} F_{j} \text { (material balances) } \\
& A y_{j} \leq b, \forall j \in J \text { (logical constraints) } \\
& F_{j} \geq 0, \forall j \in J \text { (nonnegativity constraints) } \\
& y_{j} \in\{0,1\}, \forall j \in J \text { (integrality constraints) }
\end{aligned}
$$

The cost coefficients are obtained based on the methods available in Loh et al. (2002).

\section{CASE STUDY FROM \\ MALAYSIAN \\ PETROCHEMICAL INDUSTRY}

The formulated MILP to determine the optimal sequence for olefins production is applied to a case study considering the feedstock for the petrochemical industry in Malaysia. The petrochemical industry is an important sector in Malaysia with investments about US\$9 billion from some of the worldleading manufacturers (as of July 2009). Rapid growth of the industry in Malaysia is mainly attributed to the availability of petroleum (oil and gas) reserves as feedstock, a welldeveloped infrastructure as well as the country's cost competitiveness and strategic location. The presence of major multinational companies such as BP, Shell, BASF, and Eastman highlights Malaysia's petrochemicals potential, and most of the companies operate in collaboration with PETRONAS, the Malaysian national petroleum company. Three major petrochemical zones have been established in Kertih in the Terengganu state, Gebeng in Pahang, and Pasir Gudang in Johor besides a middle distillate synthesis plant in Bintulu in Sarawak (operated by Shell). Each zone is an integrated petrochemical complex equipped with thermal crackers, synthesis gas, and aromatics facilities to produce feedstock for the products.

The proposed MILP is implemented on GAMS 24.2.2 (Brooke et al., 2012) and solved with ILOG CPLEX 12.6.o.o (IBM 2014). Two instances are considered in which each admits a feed composition based on the cracking yields of liquid naphtha feedstock and that of gaseous ethane feedstock, respectively. The economics data for both instances are given in Table 2.

Table 2. Economics data for the case study

\begin{tabular}{|l|l|}
\hline Parameter & Value \\
\hline Total feed flow rate $F^{\mathrm{F}}$ & $10,000 \mathrm{~kg} / \mathrm{h}$ \\
\hline Plantlife $L$ & $20 \mathrm{y}$ \\
\hline
\end{tabular}

Table 3. Capital cost for the tasks

\begin{tabular}{|l|l|l|l|}
\hline Task & Capital cost coefficient $\left(\$ \times 10^{5}\right)$ & Task & Capital cost coefficient $\left(\$ \times 10^{5}\right)$ \\
\hline C1 & 1.05 & C10 & 1.75 \\
\hline C2 & 1.15 & C11 & 1.75 \\
\hline C3 & 1.00 & C12 & 1.65 \\
\hline
\end{tabular}




\begin{tabular}{|l|l|l|l|}
\hline C4 & 1.20 & R1 & 0.20 \\
\hline C5 & 1.35 & R2 & 0.20 \\
\hline C6 & 1.55 & R3 & 0.25 \\
\hline C7 & 1.55 & R4 & 0.25 \\
\hline C8 & 1.45 & OCU & 8.00 \\
\hline C9 & 1.45 & PSA & 1.25 \\
\hline
\end{tabular}

\section{A. Olefins Production from Naphtha Feed}

In the first instance, we consider a feed composition based on the thermal cracking yields of a liquid naphtha feedstock. The composition is given in Table 4 in which the key in column 1 refers to a component $i$.

Table 4. Feed composition based on thermal cracking yields of a liquid naphtha feedstock

\begin{tabular}{|l|l|l|}
\hline Key & Compound & $\begin{array}{l}\text { Composition } \\
(\text { wt\% })\end{array}$ \\
\hline a & Methane $\left(\mathrm{CH}_{4}\right)$ & $15 \cdot 3$ \\
\hline b & Hydrogen $\left(\mathrm{H}_{2}\right)$ & 0.8 \\
\hline c & Ethane $\left(\mathrm{C}_{2} \mathrm{H}_{6}\right)$ & 3.8 \\
\hline d & Ethylene $\left(\mathrm{C}_{2} \mathrm{H}_{4}\right)$ & 29.3 \\
\hline e & Acetylene $\left(\right.$ ethyne) $\left(\mathrm{C}_{2} \mathrm{H}_{2}\right)$ & 0.7 \\
\hline f & Propane $\left(\mathrm{C}_{3} \mathrm{H}_{8}\right)$ & 0.3 \\
\hline g & Propylene $\left(\mathrm{C}_{3} \mathrm{H}_{6}\right)$ & 14.1 \\
\hline h & $\begin{array}{l}\text { Propadiene } \quad(m e t h y l a c e t y l) \\
\left(\mathrm{C}_{3} \mathrm{H}_{4}\right)\end{array}$ & 1.1 \\
\hline $\mathrm{j}$ & Butadiene $\left(1,3^{-} \mathrm{C}_{4} \mathrm{H}_{6}\right)$ & 4.8 \\
\hline $\mathrm{k}$ & $\begin{array}{l}n \text {-Butane }\left(\mathrm{C}_{4} \mathrm{H}_{10}\right) \quad \text { and } \quad 1- \\
\text { Butene }\left(\mathrm{C}_{4} \mathrm{H}_{8}\right)\end{array}$ & 4.5 \\
\hline l & Pyrolysis gasoline & 21 \\
\hline m & Fuel oil & 3.8 \\
\hline & & \\
\hline
\end{tabular}

The results of the naphtha processing sequences are reported in Figure 2 for the optimal solution, while Figure 3 and Figure 4 display the second and third-best solutions, respectively. To obtain the second-best sequence, we append the following integer cut as a constraint in the model to rule out the optimal sequence:
$\left(\begin{array}{l}y_{\mathrm{Feed}}^{a-m}+y_{\mathrm{Oil}}^{m}+y_{\mathrm{Quench}}^{a-l}+y_{\mathrm{C} 1 \mathrm{a}}^{a-b \mid c-l}+y_{\mathrm{C} 3 \mathrm{a}}^{c-e \mid f-l}+y_{\mathrm{C} 4 \mathrm{a}}^{c-d \mid e} \\ +y_{\mathrm{C} 8 \mathrm{a}}^{f-h \mid j-l}+y_{\mathrm{R} 2}^{f-h}+y_{\mathrm{PSA}}^{a \mid b}+y_{\mathrm{C} 10}^{c \mid d}+y_{\mathrm{C} 11}^{f \mid g}+y_{\mathrm{OCU}}^{j-l}\end{array}\right) \leq N-1$

Note that the integer value on the right-hand side of this constraint is equal to one value less than the number of columns $N$ for the optimal sequence. For instance, in our case, since there are 12 units in the optimal sequence (i.e., $N$ $=12$, see Figure 2), thus specifying the sum of the binary variables which represent selecting all the columns as less than or equal to 11 ensures that this sequence is not considered in computing a second-best sequence. Similarly, the third-best sequence is determined by specifying $N$ as 14 in Equation 16 to rule out the incumbent second best sequence solution (see Figure 3).

The optimal sequence entails the lowest total mass flow rate, which is a feature consistent with the heuristic of selecting a sequence with minimum total flows (Douglas 1988). Such a characteristic also contributes to the lowest operating cost and in this case, to the lowest total annualised cost because fewest columns are selected, which attributes to the lowest capital cost.

On the other hand, the second-best sequence, as shown in Figure 3 has two extra columns that lead to a wide range of products produced. The third best sequence registers the highest total cost because it involves the largest total flows. Moreover, relatively high acetylene and low ethylene production in this sequence entail the use of a catalytic hydrogenation reactor (task R1a) to convert acetylene to ethylene. If economically attractive, the acetylene may be recovered by extractive distillation (Kniel et al., 1984). However, in most cases, the acetylene is hydrogenated to ethylene and ethane, which involves less equipment while promoting a higher ethylene production.

The optimal sequence obtained is also in agreement with other distillation sequencing heuristics (Seader et al., 1977; 
Douglas 1985). The optimal sequence removes the lightest component first as the leading column is the demethaniser that recovers the lightest components of hydrogen and methane. This direct sequence configuration requires less energy consumption because the light materials (i.e., hydrogen and methane) are vaporised upfront besides achieving a low minimum vapour flow rate, thus decreasing the heat duties of the condensers and reboilers. The optimal sequence also obeys the heuristic of removing the most plentiful components first, because the bottom products of the demethaniser go to the deethaniser to recover the twocarbon-atom $\left(\mathrm{C}_{2}\right)$ components at the top and the threecarbon-atom $\left(\mathrm{C}_{3}\right)$ components as the bottoms, which are then directed to the depropaniser. After that, by extension, the optimal sequence conforms to the heuristic of performing the difficult separations last.

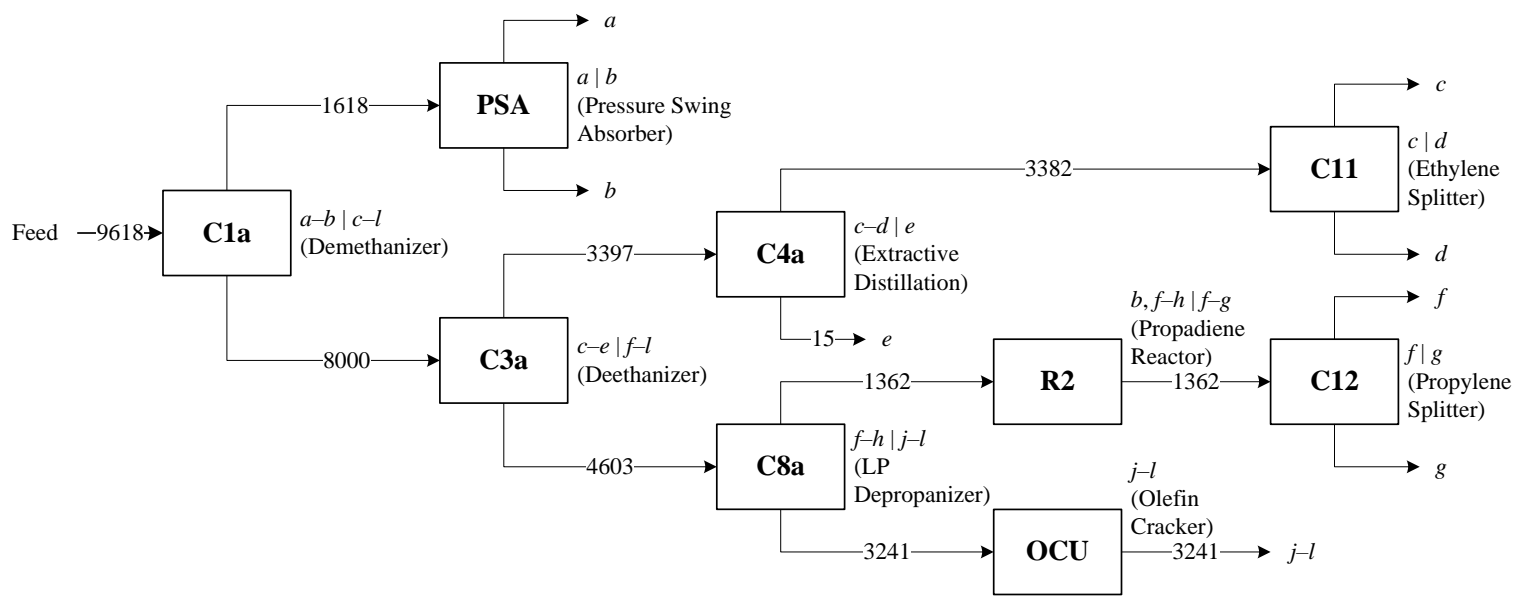

Figure 2. Optimal solution for the processing sequence of a liquid naphtha feedstock (total annualised cost $=$ MYR594.5 million/year)

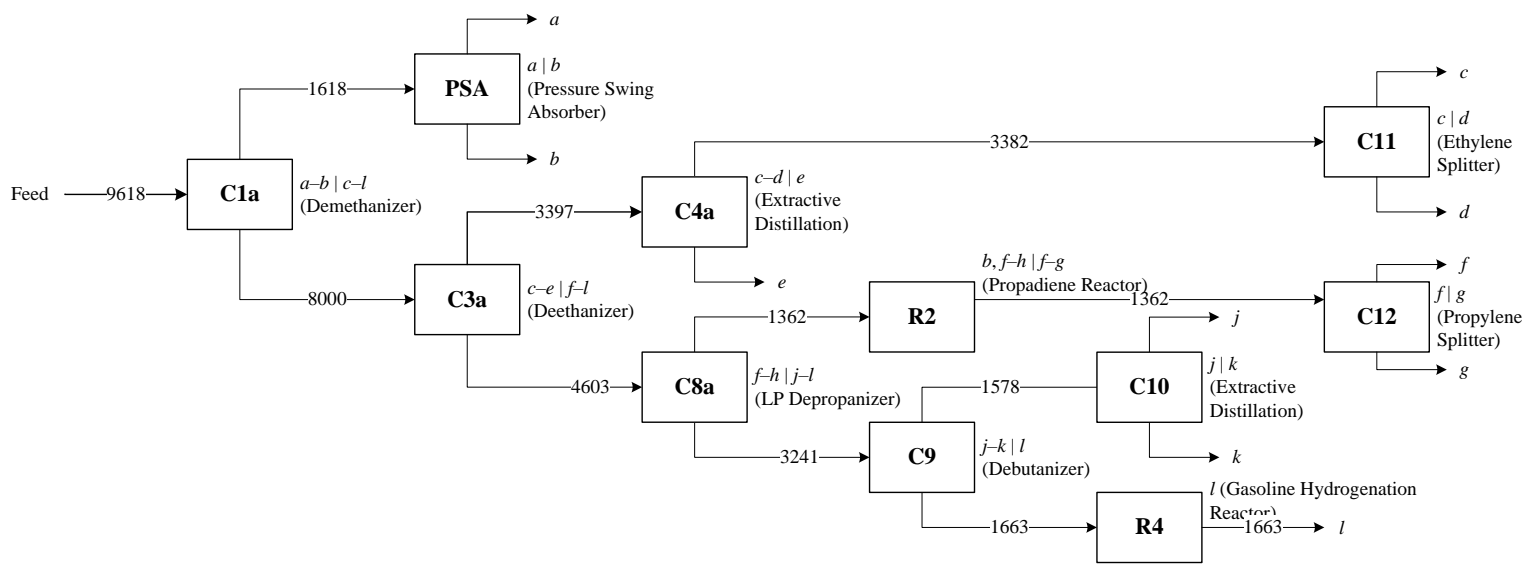

Figure 3. Second best solution for the processing sequence of a liquid naphtha feedstock (total annualised cost $=$ MYR600.5 million/year) 


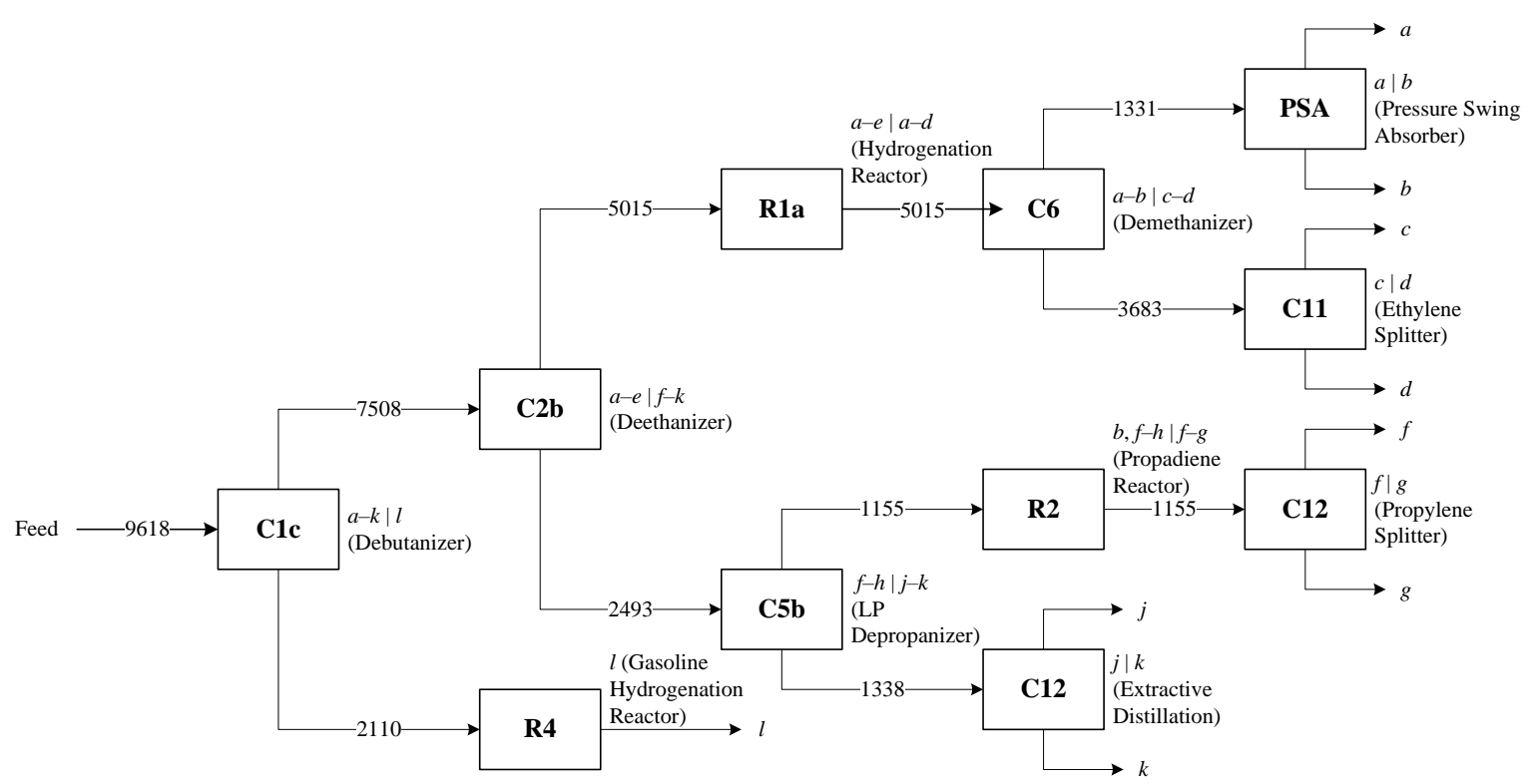

Figure 4. Third best solution for the processing sequence of a liquid naphtha feedstock (total annualised cost $=$ MYR633.5 million/year)

\section{B. Olefins Production from Ethane Feed}

In the second instance, we consider a feed composition based on the thermal cracking yields of a gaseous ethane feedstock. The feed composition is given in

Table 5 .

Table 5. Feed composition based on thermal cracking yields of a gaseous ethane feedstock

\begin{tabular}{|l|l|l|}
\hline Key & Compound & Composition(wt\%) \\
\hline a & Methane $\left(\mathrm{CH}_{4}\right)$ & 3.1 \\
\hline b & Hydrogen $\left(\mathrm{H}_{2}\right)$ & 3.4 \\
\hline c & Ethane $\left(\mathrm{C}_{2} \mathrm{H}_{6}\right)$ & 46.0 \\
\hline $\mathrm{d}$ & Ethylene $\left(\mathrm{C}_{2} \mathrm{H}_{4}\right)$ & 42.5 \\
\hline e & Acetylene $\left(\mathrm{C}_{2} \mathrm{H}_{2}\right)$ & 0.1 \\
\hline $\mathrm{f}$ & Propane $\left(\mathrm{C}_{3} \mathrm{H}_{8}\right)$ & 0.2 \\
\hline $\mathrm{g}$ & Propylene $\left(\mathrm{C}_{3} \mathrm{H}_{6}\right)$ & 1.4 \\
\hline $\mathrm{h}$ & $\begin{array}{l}\text { Propadiene }(\mathrm{methylacetyl)}) \\
\left(\mathrm{C}_{3} \mathrm{H}_{4}\right)\end{array}$ & 0.0 \\
\hline $\mathrm{j}$ & 1,3 -Butadiene $\left(\mathrm{C}_{4} \mathrm{H}_{6}\right)$ & 0.9 \\
\hline $\mathrm{k}$ & $\begin{array}{l}n \text {-Butane }\left(\mathrm{C}_{4} \mathrm{H}_{10}\right) \text { and } 1- \\
\text { Butene }\left(\mathrm{C}_{4} \mathrm{H}_{8}\right)\end{array}$ & 0.6 \\
\hline $\mathrm{l}$ & Pyrolysis gasoline & 1.8 \\
\hline $\mathrm{m}$ & Fuel oil & 0.1 \\
\hline
\end{tabular}

Figure 5 presents the optimal processing sequence computed. Similar to the use of a naphtha feedstock, an optimal solution entails the lowest total mass flow rate hence the lowest total annualised cost, which is consistent with established heuristics. Although the second-best sequence has two extra columns, it offers a wide range of products produced. Relatively high ethylene production from deethaniser (task C3a) and a low acetylene production due to ethane cracking necessitate a need for an extractive distillation column task (C4a).

The processing sequence for an ethane feedstock offers a higher ethylene yield as compared to that for a naphtha feedstock. This increases the total annualised cost because separating ethylene from ethane requires a large number of stages in a distillation column. Although ethylene is a profitable product, its production cost is high too. On the overall, the processing cost is lower for the lighter ethane feedstock as compared to that of naphtha as expected.

The model size involves 65 continuous variables, 32 binary variables, and 128 constraints. In all instances, the CPU time required is negligible. 


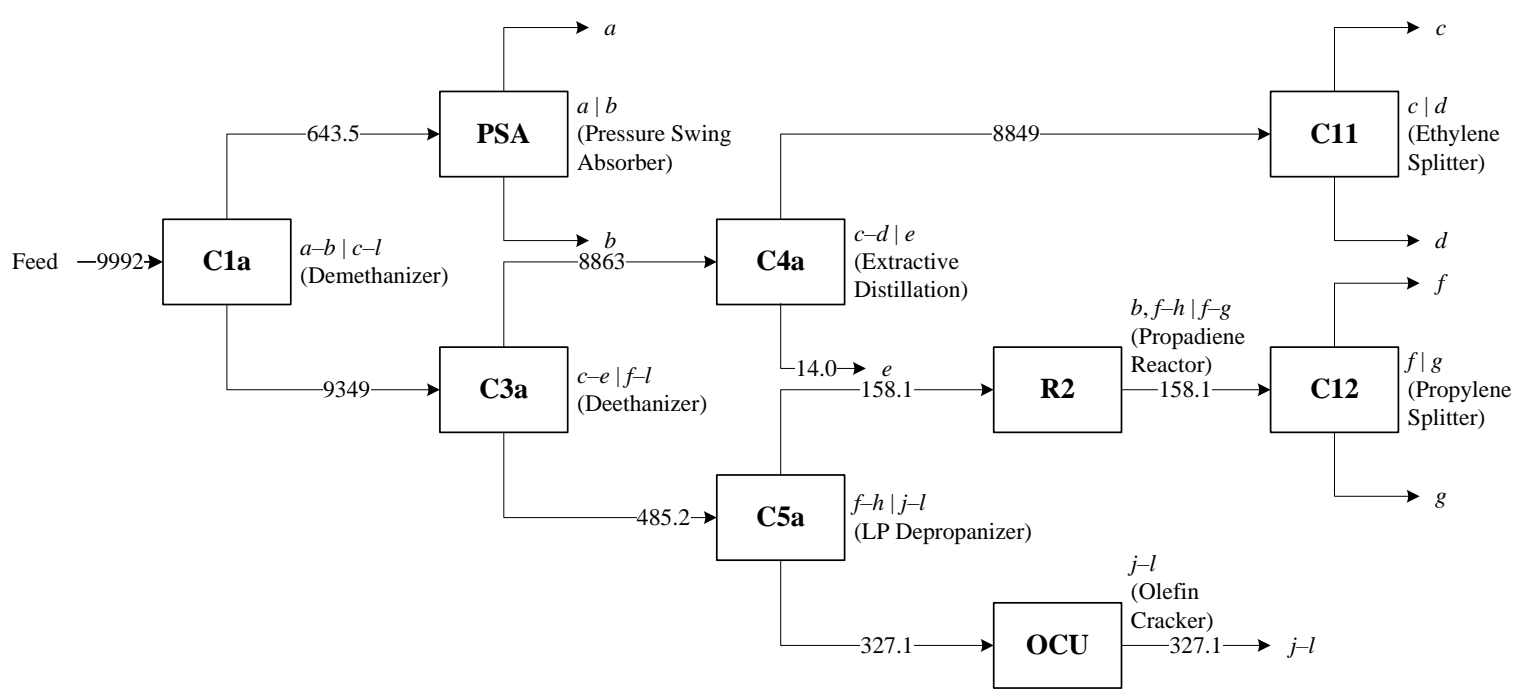

Figure 5. Optimal solution for the processing sequence of a gaseous ethane feedstock (total annualised cost $=$ MYR588.3 million/year)

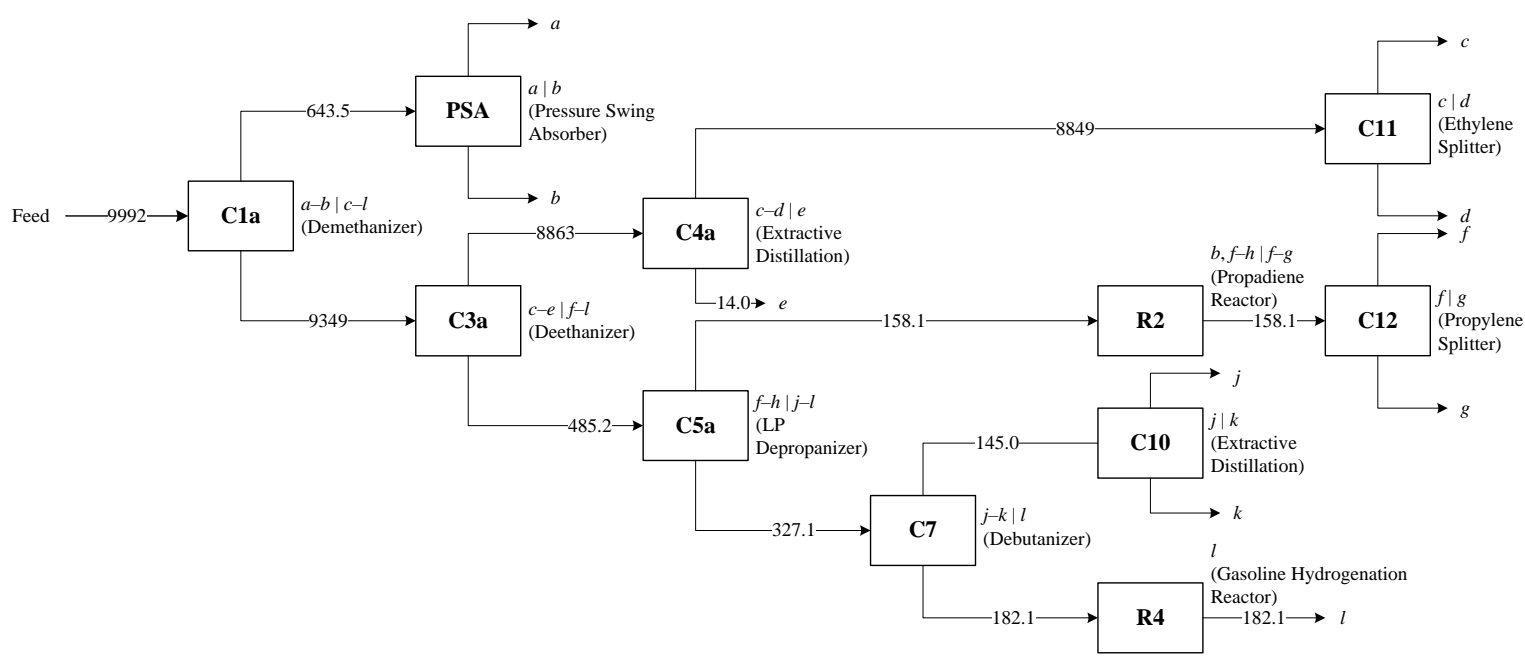

Figure 6. Second best solution for processing sequence of a gaseous ethane feedstock (total annualised cost = MYR591.5 million/year)

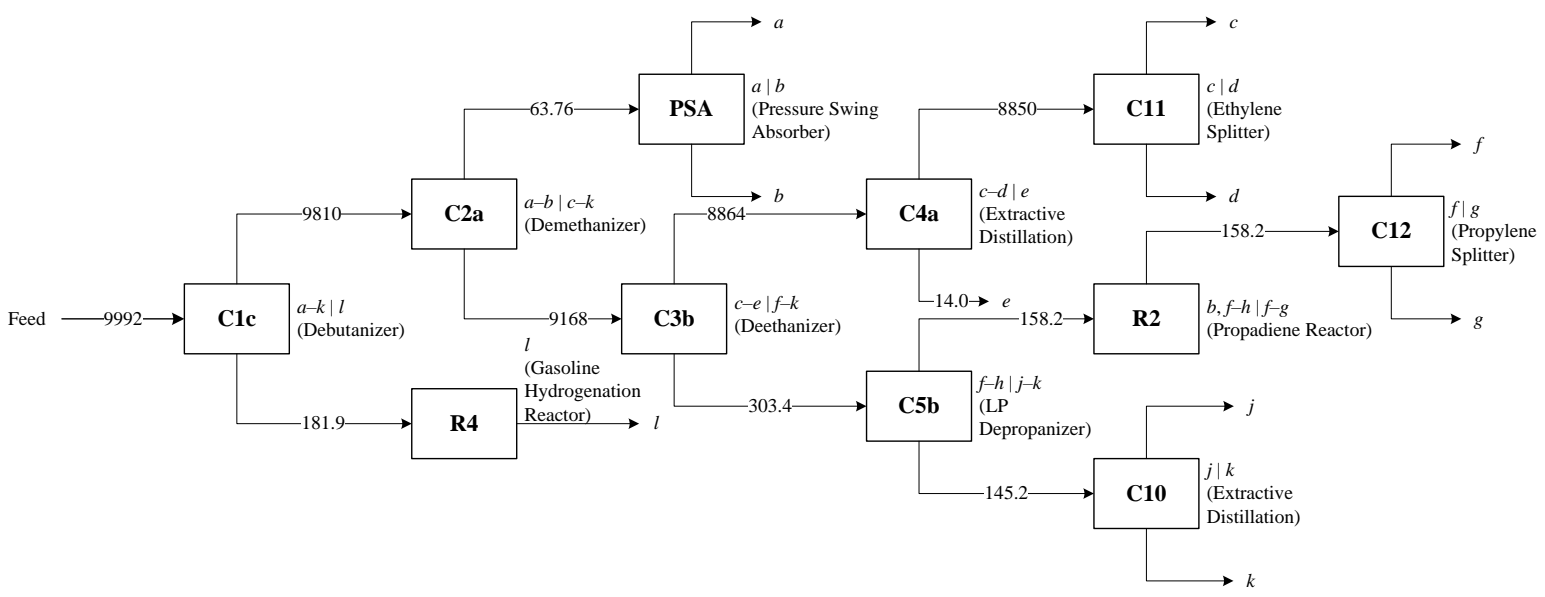

Figure 7. Third best solution for processing sequence of a gaseous ethane feedstock (total annualised cost $=$ MYR677.0 million/year) 


\section{Comparison with Industrial Configurations}

The computed optimal and second-best processing sequences for olefins production from a naphtha feed as depicted in Figure 2 and Figure 3 are similar to that of the licensed process technologies of Linde (Moulijn et al., 2001) and C-E Lummus (Hatch et al., 1981) shown schematically in Figure 8 , in which a demethaniser is employed at the front-end or the so-called "DeC1-first" configuration. The difference is that our computed configuration involves an extractive distillation unit to produce acetylene and a pressure swing absorber (PSA) for methane-hydrogen separation. The latter (PSA) is part of a typical configuration as that shown in Figure 9, which is based on Lotte Chemical Titan plant located in Pasir Gudang, Malaysia, which produces polypropylene, polyethylene, and aromatics (Lotte Chemical Titan 2018). It differs from our computed configuration (in Figure 2) in the use of a high-pressure depropaniser at the front-end (i.e., the so-called "DeC3-first" configuration), which indicates the presence of propane and heavier materials in the cracking feed (Meyers 2016).
Further, Figure 10 shows a typical configuration for olefins production from naphtha feed is based on that of the PETRONAS Chemicals Ethylene/Polyethylene located in the Kertih Integrated Petrochemical Complex in Terengganu, Malaysia, which mainly produces polyethylene. The structure is similar to our computed configuration in Figure 5 except for the absence of units to produce higher olefins, which correspondingly indicates the absence of propane and heavier materials in the cracking feed. In these figures, the units shown in dotted lines are different from the optimal solutions obtained using the approach adopted in this work.

Deciding on an optimum economic configuration between having a front-end demethaniser ("DeC1-first" configuration) or a front-end depropaniser ("DeC3-first" configuration) varies with cost and process performance as dependent on technology development, feedstock type, and plant location. On the overall, the key deciding factors include investment cost and energy consumption as well as operational flexibility, ease, safety, and serviceability (Kniel et al., 1984).

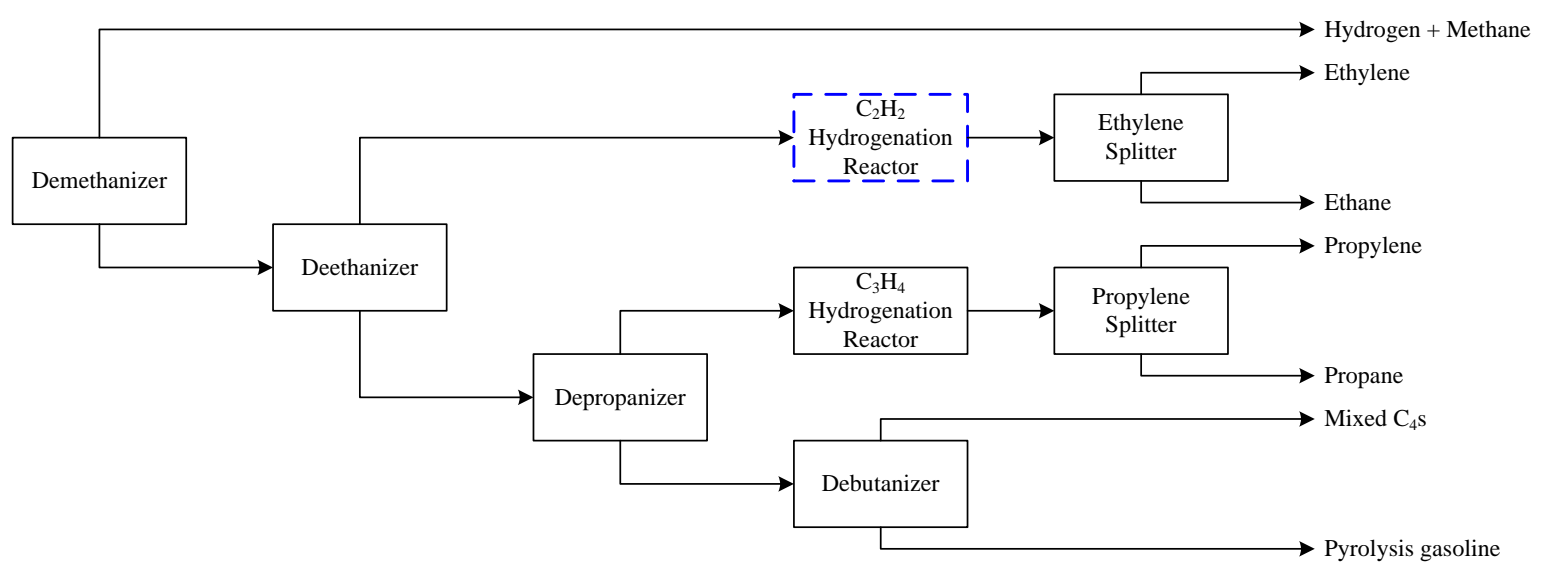

Figure 8. Schematic of a typical configuration for olefins production from naphtha feed (Hatch et al., 1981; Moulijn et al., 2001) 


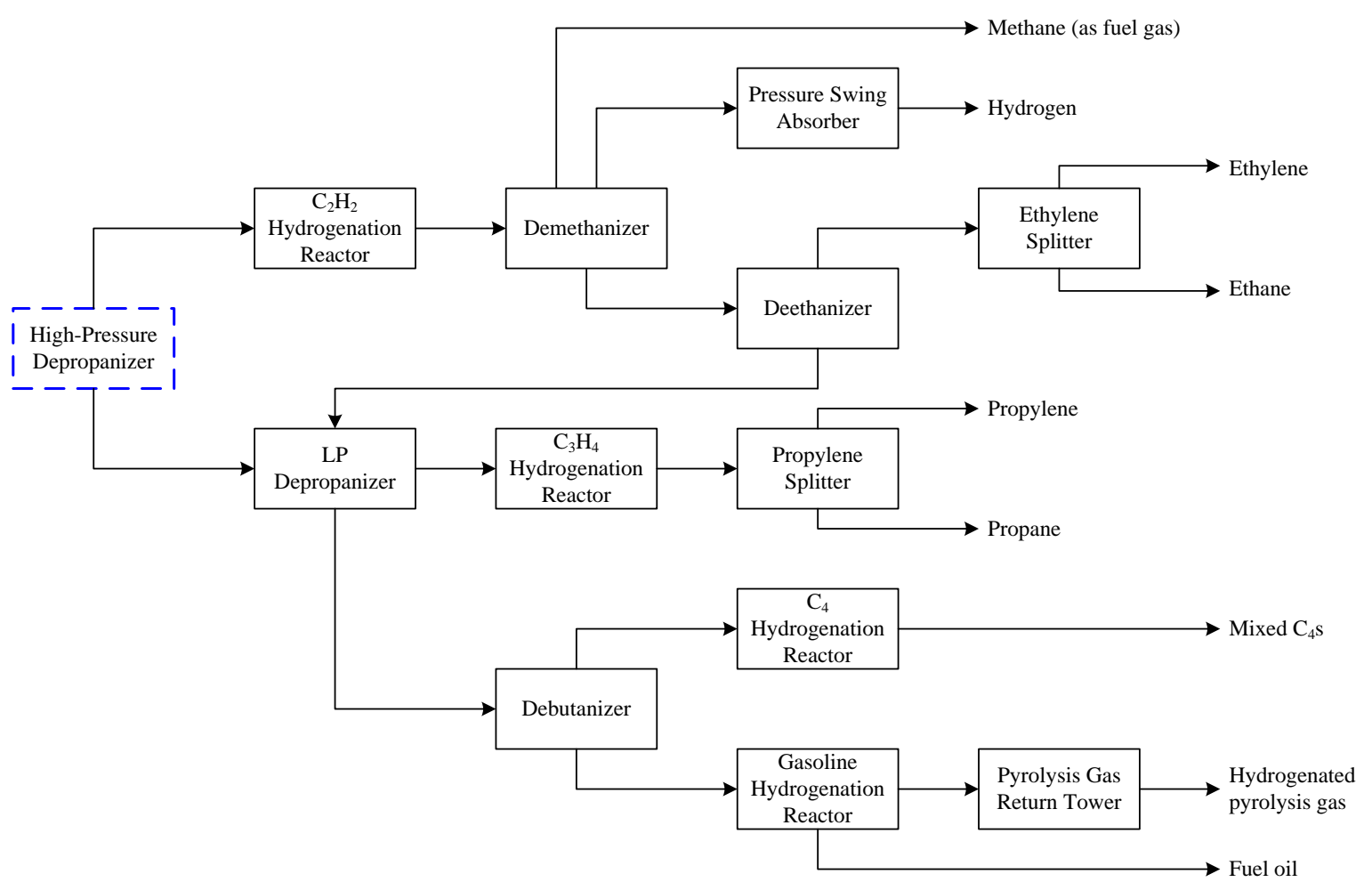

Figure 9. Schematic of a typical configuration for olefins production from naphtha feed (based on Lotte Chemical Titan)

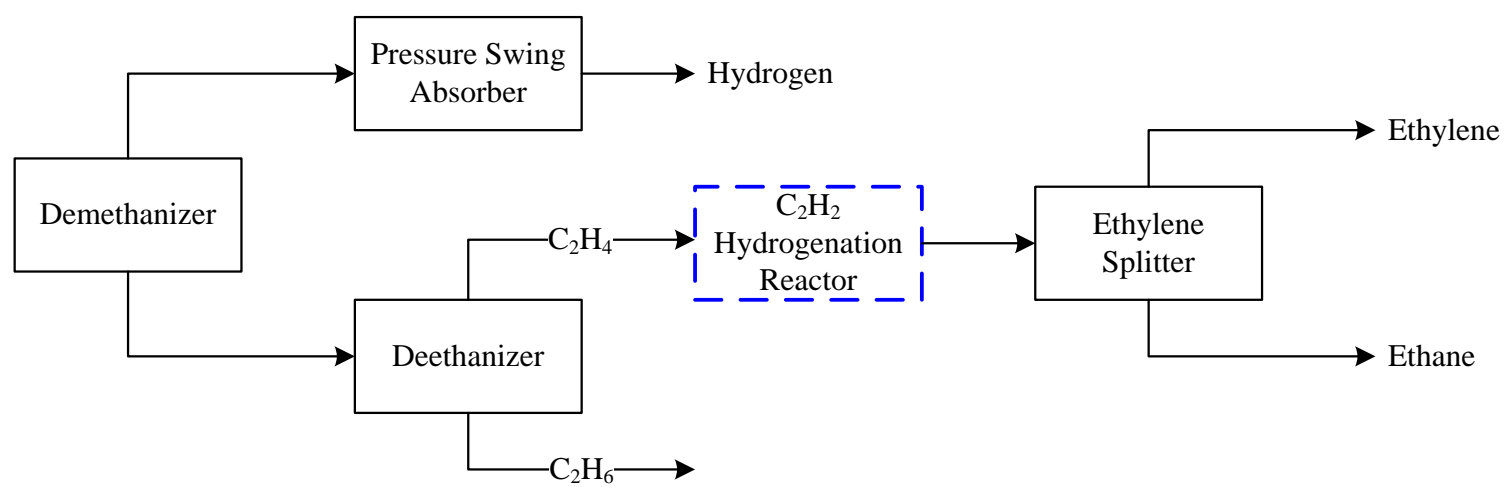

Figure 10. Schematic of typical configuration olefins production from ethane feed (based on PETRONAS Chemicals Ethylene/Polyethylene)

\section{CONCLUSION}

In this work, an MILP formulation is proposed to optimise the process synthesis of olefins production based on a superstructure that includes many possible sequences of reaction and separation tasks. In addition, physical insights are incorporated in the model by means of logical constraints that stipulate relevant design and structural specifications to aid the convergence to optimality. The optimal sequences obtained are consistent with established industrial practice and standard configurations. The results also support the general trend that processing a heavier feedstock requires higher total cost (capital and operating) than that of a lighter feedstock. 


\section{REFERENCES}

Aggarwal, A., Floudas, C.A. 1990, 'Synthesis of general distillation sequences-nonsharp separations', Comput Chem Eng, vol. 14, no. 6, pp. 631-653.

Andrecovich, MJ, Westerberg, AW 1985, 'MILP formulation for heat-integrated distillation sequence synthesis', $A I C h E$ $J$, vol. 31, no. 9, pp. 1461-1474.

Brooke, A., Kendrick, D., Meeraus, A. 2012, GAMS User's Guide, Scientific Press.

Caballero, J.A., Grossmann, I.E. 1999, 'Aggregated models for integrated distillation systems, Industrial and Engineering Chemistry Research, vol. 38, no. 6, pp. 23302344 .

Caballero, J.A., Grossmann, I.E. 2008, 'An algorithm for the use of surrogate models in modular flowsheet optimization', AIChE J, vol. 54, no. 10, pp. 2633-2650.

DOI: 10.1002/Aic.11579.

Caballero, J.A., Grossmann, I.E. 2013, 'Synthesis of Complex Thermally Coupled Distillation Systems Including Divided Wall Columns', AIChE J, vol. 59, no. 4, pp. 1139-1159.

DOI: 10.1002/Aic.13912.

Caballero, J.A., Grossmann, I.E., Keyvani, M., Lenz, E.S. 2009, 'Design of Hybrid Distillation-Vapor Membrane Separation Systems', Industrial \& Engineering Chemistry Research, vol. 48, no. 20, pp. 9151-9162.

DOI: 10.1021/Ie900499y.

Caballero, J.A., Milan-Yanez, D., Grossmann, I.E. 2005, 'Rigorous design of distillation columns: Integration of disjunctive programming and process simulators', Industrial \& Engineering Chemistry Research, vol. 44, no. 17, pp. 676o-6775.

DOI: 10.1021/Ie05008ol.
Caballero, J.A., Odjo, A., Grossmann, I.E. 2007, 'Flowsheet optimization with complex cost and size functions using process simulators', AIChE $J$, vol. 53, no. 9, pp. 2351-2366. DOI: 10.1002/Aic.11262.

Dokurno, M.G., Douglas, P.L. 1983, 'Simulation of an ethylene oligomerization reactor system using Aspen', Canadian Journal of Chemical Engineering, vol. 62, no. 6, pp. $818-824$.

Douglas, J.M. 1985, 'A hierarchical decision procedure for process synthesis', AIChE J, vol. 31, no. 3, pp. 353-362.

Douglas, J.M. 1988, Conceptual Design of Chemical Processes, McGraw-Hill, New York.

Floudas, C.A. 1987, 'Separation synthesis of multicomponent feed streams into multicomponent product streams', AIChE $J$, vol. 33 , no. 4, pp. 540-550.

Floudas, C.A., Paules IV, G.E. 1988, 'A mixed-integer nonlinear programming formulation for the synthesis of heat-integrated distillation sequences', Comput Chem Eng, vol. 12 , no. 6 , pp. 531-546.

Grossmann, I.E., Aguirre, P.A., Barttfeld, M. 2005, 'Optimal synthesis of complex distillation columns using rigorous models', Comput Chem Eng, vol. 29, no. 6, pp. 1203-1215. DOI: 10.1016/j.compchemeng.2005.02.030.

Hatch, L.F., Matar, S. 1981, From Hydrocarbons to Petrochemicals, Gulf Publishing Company, Michigan, USA. IBM ILOG CPLEX Optimizer.

Khor, C.S., Chachuat, B., Shah, N. 2012a, 'A superstructure optimization approach for water network synthesis with membrane separation-based regenerators', Comput Chem Eng, vol. 42, pp. 48-63.

DOI: 10.1016/j.compchemeng.2012.02.020.

Khor, C.S., Qi Yeoh, X., Shah, N. 2011, 'Optimal design of petroleum refinery topology using a discrete optimization 
approach with logical constraints', Journal of Applied Sciences, vol. 11, no. 21, pp. 3571-3578.

Khor, C.S., Shah, N., Mahadzir, S., Elkamel, A. 2012b, 'Optimisation of annualised retrofit incorporating reuse, regeneration and recycle strategies', Canadian Journal of Chemical Engineering, vol. 90, no. 1, pp. 137-143.

DOI: $10.1002 /$ Cjce.20651.

Kniel, L., Winter, O. 1984, 'Ethylene', eds J.J. McKetta and W.A. Cunningham, in Encyclopedia of Chemical Processing and Design, Marcel Dekker, New York.

Loh, H.P., Lyons, J., Charles W. White, I. 2002, Process Equipment Cost Estimation, Pittsburgh, PA: National Energy Technology Center, US Department of Energy.

Lotte Chemical Titan 2019, Lotte Chemical Titan (M) Sdn.

Bhd. 2018, viewed 6 January 2019, <http://www.lottechem.my/main/main.asp.>

Meyers, R.A. 2016, Handbook of Petroleum Refining Processes, 4th edn, McGraw Hill.

Moulijn, J., Makkee, M., Van Diepen, A. 2001, Chemical Process Technology, Wiley, Singapore.

Puigjaner, L., Heyen, G. 2008, Computer Aided Process and Product Engineering, Computer Aided Process and Product Engineering, vol. 1-2.

Raman, R., Grossmann, I.E. 1991, 'Relation between MILP Modelling and Logical Inference for Chemical Process Synthesis', Comput Chem Eng, vol. 15, pp. 73-84.

DOI: 10.1016/0098-1354(91)87007-V.

Ren, T., Patel, M., Blok, K. 2006, 'Olefins from conventional and heavy feedstocks: Energy use in steam cracking and alternative processes', Energy, vol. 31, no. 4, pp. 425-451. DOI: 10.1016/j.energy.2005.04.001.

Sargent, R.W.H. 1998, 'A functional approach to process synthesis and its application to distillation systems', Comput Chem Eng, vol. 22, no. 1-2, pp. 31-45.
Seader, J.D., Westerberg, A.W. 1977, 'A combined heuristic and evolutionary strategy for synthesis of simple separation sequences', AIChE J, vol. 23, pp. 951.

Smith, E.M.B., Pantelides, C.C. 1995, 'Design of reaction/separation networks using detailed models', Comput Chem Eng, vol. 19, no. SUPPL. 1, pp. 83-88.

Westerberg, A.W., Wahnschafft, O. 1996, 'Synthesis of Distillation-Based Separation Systems', in Advances in Chemical Engineering.

World L.P.G. Association (WLPGA) 2019, Exceptional Energy in Action, viewed 11 January 2019, <https://lpgapps.org/about-this-site.> 